\title{
Concepts of Borrowings in Modern Science of Linguistics, Reasons of Borrowed Words and Some of Their Theoretical Problems in General Linguistics
}

\author{
Magami Aygun ${ }^{1}$ \\ ${ }^{1}$ Department of the French Language, Azerbaijan University of Languages, Azerbaijan \\ Correspondence: Magami Aygun, Department of the French Language, Azerbaijan University of Languages, \\ Azerbaijan. E-mail: maqami_aygun@box.az
}

Received: September 27, 2015 Accepted: November 12, 2015 Online Published: November 30, 2015

doi:10.5539/ijel.v5n6p157 URL: http://dx.doi.org/10.5539/ijel.v5n6p157

\begin{abstract} linguistic loans. For this purpose, the works of many scholars have been our basis for analysis; among them there mixture of languages despite the language borders. The various social events, nomadic life, campaigns and the military services, trade, cultural exchange and other factors favor linguistic loans. possibilities of the typology of bilingualism:

a) the linguistic typology of bilingualism;

b) the sociolinguistic typology of bilingualism;

c) the typology psychological bilingualism.

This article does not pretend to fully reflect all theories that exist on linguistic borrowing.
\end{abstract}

In this article we study the problem of language contacts, the current state of some theories concerning the are French and other European scientists, scholars of the post-Soviet period. We found that the contacts cause the

In this article we considered and studied different conceptions of matter "language contact". We also approached, studying the opinions of scientists on the matter of linguistic borrowing of the structurally related and remote languages. The issue of bilingualism has been studied and studies allowed us to conclude about the different

Keywords: borrowings, coordination, linguistics, investigation

\section{Introduction}

In the development of many languages of the mankind there exist a number of extra linguistic and intra linguistic factors. Among them, are the coordinations among the languages and borrowings.

In the modern French language, in the process of borrowing by the lexical way, the languages of other peoples establish a rich source. It is clear that since the formation of human society, the people were in interrelation with one another in the form of collectives-tribes, dynasties, peoples and nations, they set up relations with one another and continuously these relations developed. In these relations being sometimes in the form of sometimes struggles and wars, trade, and culture etc and in attitudes among the people played a main role. Consequently the words, being different word forms of the same notions began to transfer from one language into the other one.

As many peoples of the world, French people too, being in close relations and attitudes with different peoples of the world in different levels, from the languages of these peoples, thousands of words passed into the French language. This process, being one of the main factors in the enrichment of the lexics of the French language, at present too is continuously going on.

Words having transferred from the other languages, partially lose some of the characteristics of the original languages in the atmosphere of the new language and accept some of the features of the language into which they enter some of them even change so much that they assume unrecognizable form.

\section{Scope of the Study}

Borrowings play a great role in the languages. At present there is not a single language, the vocabulary of which consists of its own words. If there is one, that means that it not a developed language. Associated with modern 
development peoples of the world are economically, scientifically, economically, politically are closely connected with one another. This process creates a background for approaching the languages closer to one another, resulting in borrowing words from one another.

In a situation, like this we should just quote from G. Vandersen, who wrote: "It can never happen so, that any language without being subjected to the influence of any other language could develop. On the contrary, the influence of the neighboring languages played a great role in its development". Mutual enrichment of languages is a historical inevitability and these ties obligatorily brought to the enrichment of each of these languages (Bangruce, 1917).

Similar to these thoughts before Vandries were told by G. A. Boduen do Kourtune and G. Sukhardt stating that the problem of Interrelations of languages as a result of mutually enrichment today has acquired special actuality. A number of scientists have widely learned the problem of mutual enrichment practically and theoretically. Among these scientists, people living in the near and Far East, including the representation of our national linguistics have taken active participation in these investigations. We'd think it necessary to mention the names of some of them. Among them are: A. A. Vershagin, B. V. Gornung, G. D. Desheriyev, V. M. Semchinski, G. A. Uluktenko, A. E. Kerminski, L. P. Krisin, A. A. Reformatski, B. A. Serebrennikov, G. S. Stepanov, L. V. Sherba, V. M. Jartseva and others. The scientists of foreign countries have also made their contributions to the study of mutual relations among the languages. Among them U. Wineright, A. Vashek, B. Qavranen, L. Doruna, A. Martine, E. Petrovich, A. Rosetti, K. Sandfild, O. Savajo, G. Shukhardt, E. Khaugen and others. In our national linguistics scientists such as B. Budaqov, A. S. Damirchizadeh, B. S. Hasanov, H. A. Hasanov, B. B. Ismayilov, M. Musayev, R. S. Jabbarov, A. Y. Zahidi, and others, unknown to us were engaged in the problems of Borrowings.

If we repeat the words of A. Martiken, thanks to the contacts among the languages the mutual influence of language on one another, is one of the strongest stimulus (Martine, 1960).

Y. A. Bodouen do Kurtone, while carrying out the investigation of "Mixed" character of all the languages, noted that there is not any language which is purely all in itself, there is not any language which has not any mixture at all, because mutual contacts, both among the tribes and nation, mixture of the languages consist and which by all means show themselves. As to this scholar, the main factors mixture helping the mixture of the languages consist of phenomena of different social types, which show themselves, in nomad likes in military crusades, military services, in trade and commerce, in the exchange of scientific innovations. It is a characteristic case, that, the enrichment of the languages lexically shows itself in two directions: On one hand it brings to the language on which it is mentioned, the elements of another unknown language, and on the other hand it weakness the meaning colourings peculiar to this language (Bauduen, 1963).

While bringing clarity to the problem of "mixture of languages" academician E. V. Sherba pointed out, that the concept of "mixture of languages" in Modern linguistics is one of the most undesirable cases and the scientist considers, that the term "mixture of languages" should be better if we expressed it with the term of "Mutually weakening of the languages" (Sherba, 1958).

B. Gavravnek who used the term "the mixture of languages in the widest sense" first of all was interested in the problem of interference of languages (Gavravnek, 1972).

$\mathrm{B}$, Gavravnek considers that in the condition of bilinguism the fact that languages influence on one another is a must (Gavravnek, 1972).

A. Rossetti learning the contacts among the languages is satisfied by two divisions

1) mixed language (langue mixte) - by this time mutual influence of two morphological systems is observed:

2) language with mixed element (language mélange) is such a language in which the borrowed words from other languages are observed. The author notes that mixture in the language of mixed element, first of all is linked with the language fund (Vocabulary) of the language. Under the influence of a mixed language the phonetics of the language which borrows new words, its syntax and morphology at least too in a smallest degree is subjected to the mixture. But this impact may more show itself in the vocabulary of a language; even it can completely substitute it (Rossetti, 1972). French scholar Andre Martine for the first time suggested the term of "language contact" which was widely used by Wineright. As to U. Wineright language contact is similar with the notion of bilinguism (Wineright, 1979).

U. Wineright while expressing these thoughts doesn't take into the consideration the differences among the fact under what conditions these languages were used nor the scope of their usage during their interference (Wineright, 1972). 
As to the view points of the scientists considering the contacts among languages, the most widely spread type of these contacts is the fact of usage of separately- taken elements of the language, by the way of borrowing. These elements, after a special analysis enters the system of the language borrowing the words. In this respect the investigators divide the language contacts into two: a) direct contact; b) indirect contacts and associated with these direct and indirect borrowings (Hasanov, 1975).

There exist different theories, determining the results of contacts among the languages, especially the degree of influence of these languages, their impacts on one another and other issues. The results of language contacts may result with the liquidation of one of these languages being in mutual contact. This can be by either the language of the local population which can be mastered by the migrant people, or it can be the language of the migrants which the local population may melt it within their language. In both cases the lost language leaves the traces of the peculiarities of the language, in the language by which it was conquered (Alisova, Repina, \& Tanriverdiyeva, 1982).

Besides, the terminology of the theory of language contacts discriminates "Substract" (the main language) from "superstrat" ( the language of the population).

In the history of the French language the ancient Kelt languages of Galli act as "substrat" but the language of German tribes, being franks act as "superstrat".

Both languages being in intimacy, if safeguarded, we have to deal with "adstrat" and "instart". "Adstrat" means existing side by side, being in mutual contacts, in mutual intimacy, but never dominating one on the otherlanguages.

But the event of "Instart" is intended as an event deeply influencing one language on the other. By this time none of the originality of the languages is violated (Alisova, Repina, \& Tanriverdiyeva, 1982).

Gorning who studied the contacts among the Kindred languages indicates the following types of contacts:

1) Contacts among the languages of non Kindred languages of different systems.

2) Contacts among the Kindred languages which greately differ from one another as to the grammatical structure.

3) The contacts among the closest Kindred languages having more structural similarities and elements of roots. (Gorning, 1952).

Besides there exist other typologies of the languages, influencing one on the other too. In most cases scholars mix up the mutual interrelations of languages with the results of the last ones. It is necessary to admit, that interrelation of languages is being realized in different process and by different process the elements of the language mutually influence on one another. Sometimes these impacts bring to the loss of language units and language models. These processes stimulate the tendencies in the language or may cause to the formation of obstacles for them.

A. A. Beletski Considers that it is necessary to study the one- sided influence of the interrelations among languages, because such influences cause some changes (Beletskiy, 1967).

S. Jabbarov who studied Arabic borrowings in the French language considers that in one sided language contacts influence becomes in one level in the lexic level (Jabbarov, 1984).

At last the result of the fact that two or more language are in mutual contacts is called by. Boduen de Kurtene as "language closeness", but by K. Sandfield and by the representatives of Prague linguistic school as "language union".

G. S. Stepanovtoo expressed the thought on the necessity of studying the contacts, among the languages. The author noted that some of these ties can be direct, while some others may be indirect. When the author meant direct contacts, he intended intimacy of people, speaking different languages. As to him by this time there is created such a layer, this layer the speakers of speak in the languages, in which he she is equally in intimacy. By the indirect contacts he meant the contacts in which resemblance, relying on the commonness of culture develops. Here literary translations, scientific and literary films, information of daily press, radio and television etc. play the main parts (Stepanov, 1965).

The most widely-spread language contacts are the contacts in which the language which accepts the other language, uses the separately-taken elements of the donor language. The last ones being subjected to special changes within the composition of the language which receive foreign words enter the structure of those languages. Some scientists, expressing the following thoughts consider that, if we take such types of contacts in 
comparison with one another, we may call it "abstract" but the result of interference as a language. "Superstrat" conception in this regard is not similar to any language essence (Alisova, Repina, \& Tanriverdiyeva, 1982).

Serebrennikov who made attempts to explain the essence of "Substrat" considers two types in the interlingual relations:

Marginal contact. This contact intends the contacts of two languages existing in bordering territory and which is characterized by bilinguism. In this situation the influence of one language on the other is not so strong.

Regional contact. In this respect the bearers of one language are in close contacts with the bears of the other language and are characterized by strong influence of one on the other (Serebrennikov, 1956).

L. T. Barannikova while studying the bilateral (binary) mechanism of language contacts among languages and dialects, discovers the existence of the followings during these contacts.

1) Languages of different structures, namely the languages, structures of which are different from one another typologically.

2) Languages being close to one another structurally, namely typologically similar to one another

3) Languages belonging to different languages as to structures.

4) Languages, structurally close to one another

5) Dialectsof one language (Barannikova ,1969)

In such a case, we think that we shouldn't mix up interlingual and interdialectical relations with each other. Undoubtedly, the mutual ties of the dialects of one language are different from the mutual ties of the two different languages.

The investigation object of this dissertation (thesis) is to study one-sided French-English language contacts, and also to study the influence of English on the French language in the lexic level and study of influence of these borrowings in the aspect of French circular press.

A. V. Destinskaya who was engaged in the study of the problems of bilinguism, pays attention to such factors that the study of the problems of the influences of the languages on one-another, is directly associated with the study of the history of the language of the peoples of which we deal. Undoubtedly, in this respect stages of social development of the peoples should be taken into consideration including the specific features of the intended languages as well. Alongside them the fact of being in what degree these languages are kindred must also be taken into consideration A. V. Destinskaya considers that, in any case the problem of contacts of languages with one another and the issues of bilingism in their impact to one- another also plays a special role (Destinskaya, 1956).

Gavransk, who mentioned the phenomenon of bilinguism in the interrelations of languages as a special case suggested that it was necessary that they should apply the term "bilinguism" to the collection bilinguism. The author wrote: "Of course when we deal with the mixture of languages into one-another, their mixture in this way may only take place in the collective bilinguism. Here we don't mean the borrowings of individually-taken words, because when we speak of the individually-taken words, these words even as a result of weakest language contacts, and in individual contacts may take place." B. K. Javranek in his work "Interchange of languages" notes that if we deal with lexic layer which are in close relations with one-another functionally (for example, the layer of Arab words used in the Spanish language) don't we cope with a question whether we should learn-them as a result of bilinguism or not? (Gavranek, 1972)

Following S. V. Semchinski's ideas, it would be worth mentioning that, individual bilinguism is of no importance for linguistics is unacceptable. The phenomena of interferention at first appears in the one bilingual speech and then as other pieces of news spreading among the monolingual speeches enters the system of a language (Semchinskiy, 1973).

L.P. Krisin speaking on the factors, conditioning the borrowings of the words, considers that by this time the most dominant role remains on the part of bilinguism. As to the thought of the author, this bilingism must be understood as the result of territorial contacts of the two languages, as automatically free transition of one language into the other. Such kind of transition may take place during the direct contact of bearers of two different languages (reading books, newspapers and so on in the foreign languages) (Krisin, 1965).

A number of works have been devoted to the theoretical issues of bilinguism (Sherba, 1958; Desheriyev, Vershagin). The analysis of this investigation gives us possibilities to come to the following conclusions:

*different typologies of bilinguism are possible: linguistic, sociolinguistic and psychological typologies. 
*Speaking from the linguistic view point coordinative (unmixable) and subordinative (mixed) bilinguim is intended.

*Speaking of sociolinguistic view point individual and collective bilinguisms are intended. Speaking of collective bilingism, by this time partial and total bilinguisms are intended.

*at last, speaking of psychological bilinguism, receptive (perceptive) reproductive and productive bilingisms are intended. By the way, it is necessary to note that the issues of typology of bilinguism at present too are being discussed in the pages of scientific press.

In any case study of bilinguism, being a very important problem will still remain as a very important problem and will always condition the mutual ties of the languages. The result of mutual influence of languages on each-other is called interference, which is observed in different fields of language system. The phenomenon of interference in lexic-semantic level manifests itself directly in lexic borrowings, translation of foreign normative means by the way kalka (borrowings of the models) and in the form of semantic borrowings. Thus, borrowing of the word is the most important result of the mutual influences of the languages and some of the authors, confronting the concept of borrowing word and interference, they state that they are different factors. (Aristova , 1978)

Speaking of the process of the borrowed word we mean the borrowings of lexic units by the means of another language. These words take part in the phonetic, syntactic, lexic, semantic style and in the phrase logical level of the languages, borrowing the words. Some authors give us possibilities to claim in the process of borrowings, that the most borrowed words are lexic units. For example, M. V. Belkin understands the concept of borrowing in a narrow sense of meaning, he understands it in the classic meaning, namely, he understands the transition of the lexic elements into the Arabic language. As to him, by this time not any phenomenon of substitution in the word takes place scientifically or relatively morphological substitution takes place. By this time complete subordination of the borrowed word into the word forming structure of the languages borrowing the words is observed.

The existence of Latin, Greek, Arab, Turkic, Italian, Spanish, Portuguese, Persian, English, Russian, French, etc. languages in the world languages is just explained by this reason. Thus, in the vocabulary fund of each language besides the existence of native words we see the existence of borrowings in this or that account. One of the reasons of lexic borrowings is an extra linguistic factor. By this time among the peoples political, economical, commercial and cultural ties ate much closer. The second reason is an intro linguistic factor which plays are of the main roles during the borrowing of words. In the linguistic literature the problems of borrowings are studied both by the formal (phonetic, morphological, semantic, understanding) and by functional criteria.

Even U. Wineright suggests the necessity of learning the lexic borrowings from the view of the means leading them to the mechanism of interference, including the view of their mixture into the language which borrows the, Phonetically, grammatically, semantically and from the view of stylistics (Wineright, 1972).

Different classifications indicating the degree of formal and functional understanding of the borrowings in the language which borrows them exist. For example, the authors suggesting these classifications, such as E. E. Berjakova, L. A. Vayonova, L. Kutiani and others, determined the unit of the borrowed word and its functional sphere, the form of the borrowed word, the source of the borrowed word and semantic characteristics of the word.

The last classification of J. V. Arnold Divides his classification into three parts: 1) completely assimilated ones; 2) partially assimilated ones; 3 ) exotisms (Arnold, 1966).

The character of the languages being in mutual relations, their structural and genetic commonness makes a special influence on the process of borrowings. The languages, proving the existence of such a common opinion shows that during the contacts of Kindred languages with one another the borrowed lexic units more easily are mastered (Dubois, 1963)

Orelyon Sovajo states that in the borrowings two classifications exist: He considers that the first of them are the necessary borrowings: "Emprunts necessary" but the second ones are redundant (Unnecessary) borrowings "Emprunts superflux" (Souvageat Au, 1964)

In Learning of the lexics of a foreign language and in its investigation, the role of French scholar Pyer Giron is great. On the basis of his investigation stands word-notion and the object stating it. This scientist suggests the followings:

a) borrowing the conception together with word 
b) non reception of conception together with words, words are borrowed without conception

c) the conception of words are borrowed but words are not borrowed:

d) Frenchalization of the borrowed words.

e) Frenchalization of the borrowed conception (Guirand, 1971)

As to the classification of Hei Dörnan borrowings may be divied into two parts: the first, words, making impression as foreign words. Hui Dorna calls them as Peregrinisms. These words are the words not being fully mastered. The second ones are words which have been fully assimilated (Deroy, 1956).

\section{Conclusion}

The analysis of the linguistic literature makes it possible for us to say that the term "borrowed word" is a term having many plans and many branchess of entering the borrowed structure of a foreign language which has borrowed the word and the result of this processes. In this dissertation (thesis) we agree with the thought of those investigators, who intend the entrance of the lexic units of a foreign language into another language by the notion of the term "the borrowed word". We act from the criteria that the process of "lexic borrowing" is a complicated process and as a result of this is fully intergrated into the system of this language which receives the foreign words. Undoubtedly, in this respect it intends the entrance of foreign words into the phonetic, morphological and semantic system of the language, which receives the foreign words.

\section{References}

Alisova, T. B., Repin, T., \& Tanrverdiev, M. (1982). Introduction to Roman philology. Moscow: Higher School.

Aristova, V. M. (1978). Anglo-Russian language contacts (Anglicisms in Russian). L. Izd. Univ

Arnold, I. V. (1966). Lexicology of Modern English. L. Education.

Barannikova, L. I. (1969). On the language contacts. Mutual influence and mutually enrichment of the languages of USSR, Moscow, Science.

Beletsky, A. (1967). Genesis and etymology. Problems of Linguistics. Reports and posts of Soviet scientists at the Tenth International Congress of Linguists. Science.

Deroy, L. (1956). Emprunt linguistique. P. Belles Lettres.

Desnitskaya, A. V. (1956). On the issue of interrelation of languages. Reports and information of the institute of linguistics of Academy of Sciences of USSR. Moscow.

Dubois, J. (1963). Borrowings in French. Literary Information.

Gavranek, B. K. (1972). To the problem of mixing languages (trans. from German). Innovations in linguistics (Vol. 6). M. Progress.

Gornung, B. V. (1952). On the issues of types and forms of mutual influence of languages. Reports and information of the Institute of linguistics of Academy of Sciences of USSR. Moscow.

Guiraud, P. (1971). Foreign words (2nd ed.). P. University Press of France.

Hasanov, B. S. (1975). Process of borrowing and particularly the development of loan words in the language (based on the Turkic lexical elements in German). Author. Diss ... cand. filol. Sciences. Baku.

Haugen, E. (1972). Language contact (trans. from English). Innovations in linguistics (Vol. 6). M. Progress.

Jabbarov, R. J. (1984). Arabian borrowing in the French language. Diss ... cand ... filol ... Sciences. Baku.

Krysin, L. P. (1965). The issues of foreign language borrowings in the Russian vocabulary of the Soviet era. Author. Diss ... cand. filol. Sciences. M.

Martin, A. (1960). Principles savings phonetic changes (trans. From French). M. Publishing House of Foreign literature.

Rosetti, A. (1972). Mixed language and mixing languages (trans. from French). Innovations in linguistics (Vol. 6). M. Progress.

Semchinsky, S. V. (1973). Semantic interferences of languages Synopsis diss. Doctor of Philological Sciences, Kiev.

Serebrennikov, B. A. (1956). Problems of Substrat. Reports and information of the Institute of Linguistics of Academy of Sciences. Moscow. 
Sherba, L. V. (1958). On the concept of mixing languages. Selected works on linguistics and phonetics.

Stepanov, S. (1965). The structure of the French language.

Vendryes, J. (1937). Language. M. Sotsekgiz.

Weinright, W. (1972). Monolingualism and multilingualism (trans. from English). Innovations in linguistics (Vol. 6). M. Progress.

Weinright, W. (1979). Language contacts. K. Vishcha school.

\section{Copyrights}

Copyright for this article is retained by the author(s), with first publication rights granted to the journal.

This is an open-access article distributed under the terms and conditions of the Creative Commons Attribution license (http://creativecommons.org/licenses/by/3.0/). 